\title{
Modelo de dobramento de proteína em jogo computacional
}

\author{
Renan Martinez da Luz ${ }^{1}$ \\ Diana F. Adamatti ${ }^{1}$ \\ Adriano V. Werhli ${ }^{1}$
}

\begin{abstract}
Resumo: As proteínas desempenham um papel fundamental na natureza e a descoberta de suas funcionalidades e seus comportamentos ainda inexplorados necessitam serem estudados. Portanto, este trabalho tem como objetivo o desenvolvimento de um jogo sério de dobramento de proteína para ser usado como ferramenta de alimentação em uma base de dados. Esta base de dados pode ser usada como entrada em algoritmos estatísticos que através de suas metodologias possam extrair conhecimentos e regras de dobramento de proteína. Chegou-se a conclusão que através desta ferramenta é possivel extrair conhecimento e regras de dobramento de proteínas da inteligencia humana através de um jogo sério.
\end{abstract}

Palavras-chave: Aplicações Web, Dobramento de Proteínas, Jogos Sérios.

\begin{abstract}
Proteins play a fundamental role in nature and the discovery of their functionalities and their unexplored behaviors must be studied. Therefore, this work aims to develop a serious game to protein folding to be used as a tool to increase a database. This database can be used as input in statistical algorithms that by their methodologies extract knowledge and rules about protein folding. Using our tool, we can conclude that is possible to extract knowledge and rules of protein folding of human intelligence through a serious game.
\end{abstract}

Keywords: Protein Folding, Serious Games, Web Applications.

\section{Introdução}

As proteínas desempenham um papel fundamental na natureza e essas estruturas, compostas por aminoácidos, participam em muitas tarefas importantes como, garantir o correto funcionamento das células. A descoberta de suas funcionalidades e seus comportamentos ainda inexplorados, desperta muito interesse em áreas envolvidas como a biologia, empresas de fabricação de medicamentos e até mesmo a produção de outras proteínas [1]. Segundo Cooper et al. [2] ainda existe uma vasta gama de problemas ainda não resolvidos a respeito da predição dessas estruturas, soluções que são essenciais para a vida do ser humano.

Mediante as limitações tecnológicas para simular dobramentos das estruturas das proteínas, foi criado em 2010 o jogo sério chamado "Fold it"com objetivo de capturar técnicas de dobramento de proteína através da inteligência humana [2], disponibilizando aos jogadores, estruturas completas de proteínas em 3D. A inteligência humana, em um âmbito científico, é a capacidade de seres humanos de raciocinar, planejar, solucionar problemas e abstrair ideias por conta própria [3] sem mesmo ter conhecimento do problema científico a sua frente e a real solução do mesmo, sendo assim, até mesmo pessoas comuns conseguem gerar e elaborar respostas de problemas ainda não solucionados pela ciência.

Devido as dificuldades de estudar as complexas estruturas das proteínas com seus inúmeros aminoácidos, foi criado por Dill [4] o modelo HP (Hidrofóbico-Polar), que simplifica as estruturas em um modelo 2D apresentando-as apenas em forma de sequência binária de aminoácidos, com isso, tornando as estruturas mais simples e facilitando sua predição.

\footnotetext{
${ }_{1}^{1}$ Programa de Pós-Graduação em Modelagem Computacional (PPGMC), Universidade Federal do Rio Grande (FURG) - Rio Grande (RS) Brasil

\{renanml@hotmail.com\}\{dianaada, werhli@gmail.com\}
}

http://dx.doi.org/10.5335/rbca.v9i1.6692

Revista Brasileira de Computação Aplicada (ISSN 2176-6649), Passo Fundo, v. 9, n. 1, p. 42-51, abr. 2017 
Deste modo, foi implementado um jogo sério de dobramento de proteínas no modelo HP proposto por Dill [4]. O jogo foi desenvolvido em linguagens Web para facilitar seu acesso em salas de aula e para evitar possíveis incompatibilidades com sistemas operacionais. Após o refinamento da jogabilidade e os ajustes finais, foram realizadas diversas partidas no jogo, obtendo-se um bom volume de dados, totalizando 44 jogadores que realizaram 401 jogos.

\section{Referencial Teórico}

\subsection{Dobramento de Proteínas}

O dobramento de proteína é um processo onde uma proteína assume a sua configuração funcional através de sua estrutura. As moléculas de proteínas são cadeias heterogêneas não ramificadas de aminoácidos e para que possa desempenhar uma função, a estrutura primária deve assumir uma forma tridimensional específica, sendo capazes de realizar a sua função biológica $[5,6,7,8,9]$.

Portanto, a compreensão destas características é de suma importância para varias áreas, como a da saúde, onde seria possível a criação de drogas inteligentes, entendimento de algumas doenças como câncer, mal de Alzheimer, mal de Parkinson e diabetes tipo II, que são causadas por proteínas aglomeradas e mal dobradas, que não desempenham corretamente sua função no organismo [5, 6, 7, 8, 10, 11].

\subsection{Modelo Hidrofóbico-Polar Bidimensional}

O Modelo Hidrofóbico-Polar Bidimensional (Modelo HP) é um modelo que tem como característica trabalhar com uma sequência binária de aminoácidos "H"(hidrofóbicos, apolares) ou "P"(hidrofílicos, polares), reduzindo o alfabeto de vinte aminoácidos em apenas dois. Baseia-se na crença de que a maior contribuição para a energia da conformação nativa de uma proteína é devido às interações entre os aminoácidos hidrofóbicos, que tendem a se proteger de algum solvente de seu ambiente, movendo-se para o núcleo da estrutura e sendo envolvidos pelos aminoácidos hidrofílicos que tendem a permanecer na superfície da estrutura 3D [4, 12].

Tabela 1: Sequências HP compiladas [13]

\begin{tabular}{|c|c|c|c|}
\hline Nome & Sequência & Tamanho & Energia \\
\hline S1 & $\mathrm{H}_{2} \mathrm{P}_{5} \mathrm{H}_{2} \mathrm{P}_{3} \mathrm{HP}_{3} \mathrm{HP}$ & 18 & -4 \\
\hline S1 & $\mathrm{HPHPH}_{3} \mathrm{P}_{3} \mathrm{H}_{4} \mathrm{P}_{2} \mathrm{H}_{2}$ & 18 & -8 \\
\hline S3 & $\mathrm{PHP}_{2} \mathrm{HPH}_{3} \mathrm{PH}_{2} \mathrm{PH}_{5}$ & 18 & -9 \\
\hline S4 & $\mathrm{HPHP}_{2} \mathrm{H}_{2} \mathrm{PHP}_{2} \mathrm{HPH}_{2} \mathrm{P}_{2} \mathrm{HPH}$ & 20 & -9 \\
\hline S5 & $\mathrm{H}_{3} \mathrm{P}_{2} \mathrm{HPHPHP}_{2} \mathrm{HPHPHPPH}_{\mathrm{PHP}}$ & 20 & -10 \\
\hline S6 & $\mathrm{H}_{2} \mathrm{P}_{2} \mathrm{HP}_{2} \mathrm{HP}_{2} \mathrm{HP}_{2} \mathrm{HP}_{2} \mathrm{HP}_{2} \mathrm{HP}_{2} \mathrm{H}_{2}$ & 24 & -9 \\
\hline S7 & $\mathrm{P}_{2} \mathrm{HP}_{2} \mathrm{H}_{2} \mathrm{P}_{4} \mathrm{H}_{2} \mathrm{P}_{4} \mathrm{H}_{2} \mathrm{P}_{4} \mathrm{H}_{2}$ & 25 & -8 \\
\hline S8 & $\mathrm{P}_{3} \mathrm{H}_{2} \mathrm{P}_{2} \mathrm{H}_{2} \mathrm{P}_{5} \mathrm{H}_{7} \mathrm{P}_{2} \mathrm{H}_{2} \mathrm{P}_{4} \mathrm{H}_{2} \mathrm{P}_{2} \mathrm{HP}_{2}$ & 36 & -14 \\
\hline S9 & $\mathrm{P}_{2} \mathrm{HP}_{2} \mathrm{H}_{2} \mathrm{P}_{2} \mathrm{H}_{2} \mathrm{P}_{5} \mathrm{H}_{1} 0 \mathrm{P}_{6} \mathrm{H}_{2} \mathrm{P}_{2} \mathrm{H}_{2} \mathrm{P}_{2} \mathrm{HP}_{2} \mathrm{H}_{5}$ & 48 & -23 \\
\hline S10 & $\mathrm{H}_{2} \mathrm{PHPHPHPH}_{4} \mathrm{PHP}_{3} \mathrm{HP}_{3} \mathrm{HP}_{4} \mathrm{HP}_{3} \mathrm{HP}_{3} \mathrm{HPH}_{4} \mathrm{PHPHPHPH}_{2}$ & 50 & -21 \\
\hline S11 & $\mathrm{P}_{2} \mathrm{H}_{3} \mathrm{PH}_{8} \mathrm{P}_{3} \mathrm{H}_{1} 0 \mathrm{PHP}_{3} \mathrm{H}_{1} 2 \mathrm{P}_{4} \mathrm{H}_{6} \mathrm{PH}_{2} \mathrm{PHP}$ & 60 & -36 \\
\hline S12 & $\mathrm{H}_{1} 2 \mathrm{PHPHP}_{2} \mathrm{H}_{2} \mathrm{P}_{2} \mathrm{H}_{2} \mathrm{P}_{2} \mathrm{HP}_{2} \mathrm{H}_{2} \mathrm{P}_{2} \mathrm{H}_{2} \mathrm{P}_{2} \mathrm{HP}_{2} \mathrm{H}_{2} \mathrm{P}_{2} \mathrm{H}_{2} \mathrm{P}_{2} \mathrm{HPHPH} \mathrm{H}_{1} 2$ & 64 & -42 \\
\hline S13 & $H_{4} P_{4} H_{1} 2 P_{6} H_{1} 2 P_{3} H_{1} 2 P 3 H_{1} 2 P_{3} H P_{2} H_{2} P_{2} H_{2} P_{2} H P H$ & 85 & -53 \\
\hline S14 & $\mathrm{P}_{6} \mathrm{HPH}_{2} \mathrm{P}_{5} \mathrm{H}_{3} \mathrm{PH}_{5} \mathrm{PH}_{2} \mathrm{P}_{4} \mathrm{H}_{2} \mathrm{P}_{2} \mathrm{H}_{2} \mathrm{PH}_{5} \mathrm{PH}_{1} 3 \mathrm{PH}_{7} \mathrm{P}_{1} 1 \mathrm{H}_{7} \mathrm{P}_{2} \mathrm{HPH}_{3} \mathrm{P}_{6} \mathrm{HPH}_{2}$ & 100 & -48 \\
\hline S15 & $\mathrm{P}_{3} \mathrm{H}_{2} \mathrm{P}_{2} \mathrm{H}_{4} \mathrm{P}_{2} \mathrm{H}_{3} \mathrm{PH}_{2} \mathrm{PH}_{2} \mathrm{PH}_{4} \mathrm{P}_{8} \mathrm{H}_{6} \mathrm{P}_{2} \mathrm{H}_{6} \mathrm{P}_{9} \mathrm{HPH}_{2} \mathrm{PH}_{1} 1 \mathrm{P}_{2} \mathrm{H}_{3} \mathrm{PH}_{2} \mathrm{PHP}_{2} \mathrm{HPH}_{3} \mathrm{P}_{6} \mathrm{H}_{3}$ & 100 & -50 \\
\hline
\end{tabular}

Apesar da simplicidade do modelo HP, o processo de dobramento tem semelhanças de comportamento com o processo de dobramento no sistema real. O modelo HP tem sido usado pelos químicos para avaliar novas hipóteses de formação de estrutura das proteínas $[4,12,14]$.

A energia de uma estrutura no modelo HP depende do número e posição de aminoácidos hidrofóbicos que ocupam os pontos de uma grade onde a estrutura se encontra. A Figura 1 mostra um modelo HP 2D em que a estrutura da proteína ilustrada contém 18 aminoácidos simplificados, que ocupam os pontos da grade, sendo que 
Figura 1: Ligação hidrofóbica em uma estrutura 2D modelo HP.

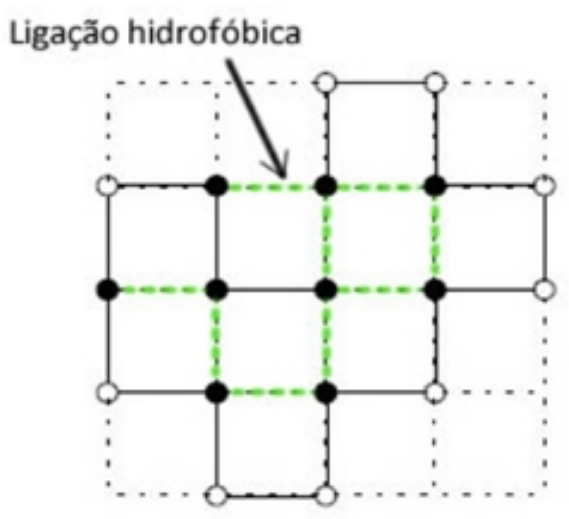

9 destes aminoácidos são hidrofóbicos. Se existem dois aminoácidos hidrofóbicos em pontos de grade adjacentes, mas que não são adjacentes na sequência de aminoácidos, então se forma uma ligação hidrofóbica simbolizadas pelos traços verdes $[4,12]$.

Benchmark é uma compilação de sequências onde é possível comparar resultados de vários modelos discretos ajudando a chegar na solução de problemas ainda não resolvidos a respeito das estruturas das proteínas. Na Tabela 1 pode-se ver a quantidade de resíduos e a menor energia encontrada para cada sequência [13].

\subsection{Jogos sérios}

Atualmente, existe uma grande tendência no âmbito científico de criar projetos de pesquisa que utilizam jogos computacionais como ferramenta para se obter resultados científicos. Um jogo sério transforma problemas científicos em quebra-cabeças e os fornece em um mecanismo de jogo, fazendo com que jogadores não-especialistas resolvam estes problemas $[15,16,17,18,19]$.

Dr. Montes, criador do jogo sério Molecular Jig² compartilhou na discussão Montes (2014) um pouco de sua experiência em jogos sérios dizendo que a criação de um jogo de computador de sucesso, muitas vezes requer tempo e esforço considerável, tanto no desenvolvimento dos conceitos, bem como na implementação e explicou também o processo de desenvolvimento utilizado por ele para desenvolver o jogo Molecular Jig.

No início, elabora os objetivos de aprendizagem e escolhe um mecanismo de jogo. Para ensinar de forma mais eficaz, escolhe um mecanismo de jogo que vai exigir aos estudantes utilizar fatos e conceitos a serem aprendidos, a fim de ganhar o jogo. Uma vez que os objetivos de aprendizagem e mecanismo de jogo são escolhidos, são criados protótipos e testados pela equipe e em seguida com membros do público-alvo. Neste processo são realizadas observações e acompanhamento de dúvidas com os membros para avaliar o mecanismo de jogo. Caso os jogadores não conseguirem identificar o objetivo do jogo por conta própria e não obter condições de vitória no ambiente, então, o mecanismo é muito complexo ou mal elaborado. Durante cada ciclo de iteração é realizada consultas com cientistas e educadores a respeito da experiência adquirida.

\subsection{Aplicações para Web}

As Aplicações Web são sistemas computacionais desenvolvidos para serem utilizados através de qualquer Browser sendo disponibilizadas por intermédio de um servidor.

Estas aplicações são inseridas, na sua maioria, em Servidores HTTP Apache que desempenham o papel de um Web host, ficando assim acessível para qualquer pessoa que tenha internet disponível em seu computador. As tecnologias mais recentes utilizadas nas aplicações são HTML5, CSS3, JavaScript e MYSQL. O usuário utiliza

\footnotetext{
${ }^{2}$ http://www.molecularjig.com/
} 
a aplicação com o mecanismo de requisição e resposta (Figura 2) onde o browser envia a solicitação HTTP do usuário e o servidor o responde com páginas HTML, imagens, documentos PDF e ou dados armazenados no banco de dados [20].

De forma geral, as aplicações web são constituídas e desenvolvidas em duas etapas: front-end e back-end. Front-end é a interface que é gerada na tela do usuário processada/compilada pelo back-end, que por sua vez serve para se comunicar com o servidor através de processos requisitados pelo usuário por intermédio do front-end, assim obtendo uma comunicação como mostra a Figura 2.

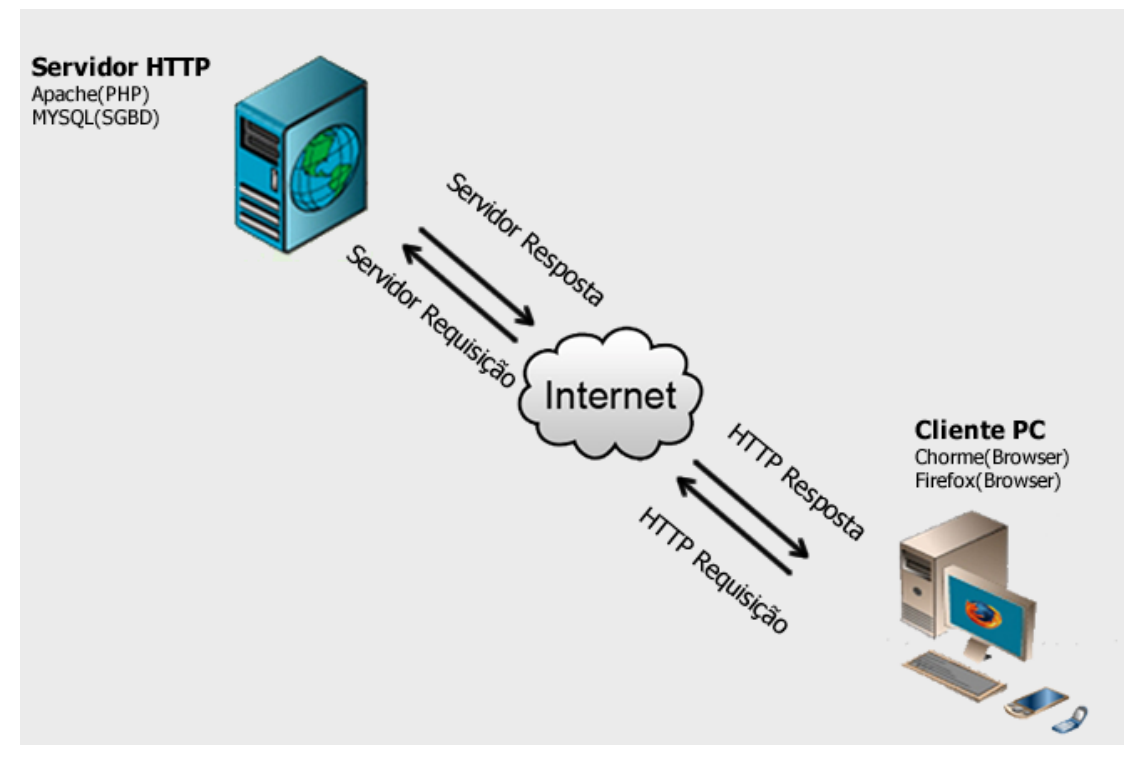

Figura 2: Fluxograma do mecanismo de requisição e Resposta Cliente-Servidor

Pode-se considerar que diferente dos programas/aplicações locais mais utilizados na atualidade, as Aplicações Web desenvolvidas com uso das tecnologias mais recentes mostra-se facilitar o acesso e a compatibilidade, pois podem ser utilizadas independentemente do sistema operacional ou do navegador utilizados pelo usuário e sem ter a necessidade de instalação em seu computador. Também mantém a compatibilidade com aparelhos de celular e tablets, muito utilizados nos dias de hoje [21, 22].

Portanto, este projeto utilizou linguagens web para o desenvolvimento do jogo sério para ser de fácil utilização na obtenção dos dados necessários.

\section{Desenvolvimento}

Nesta seção são apresentadas as técnicas utilizadas na elaboração do jogo sério de dobramento de proteína assim como a réplica dos comportamento e estruturas das proteínas modelo HP em sua interface.

\subsection{Banco de dados}

Na Figura 3 pode-se ver o modelo relacional da estrutura do banco de dados que contém quatro tabelas com suas relações e atributos, seguido de suas especificações.

- Tabela Usuario: utilizada para o armazenado dos dados de cadastro dos jogadores no site. Ela também possui um relacionamento de 1:N com a Tabela Jogos, onde um jogador contém vários jogos e um jogo contém apenas um jogador.

- Tabela Proteinas: armazena as estruturas das proteínas da tabela 1 que são fornecidas aos jogadores. Cada estrutura possui seu tamanho, sua sequência HP e sua energia máxima seguindo a metodologia das estruturas.

Revista Brasileira de Computação Aplicada (ISSN 2176-6649), Passo Fundo, v. 9, n. 1, p. 42-51, abr. 2017 
Figura 3: Modelo de relacionamento do banco de dados do jogo de dobramento de proteína

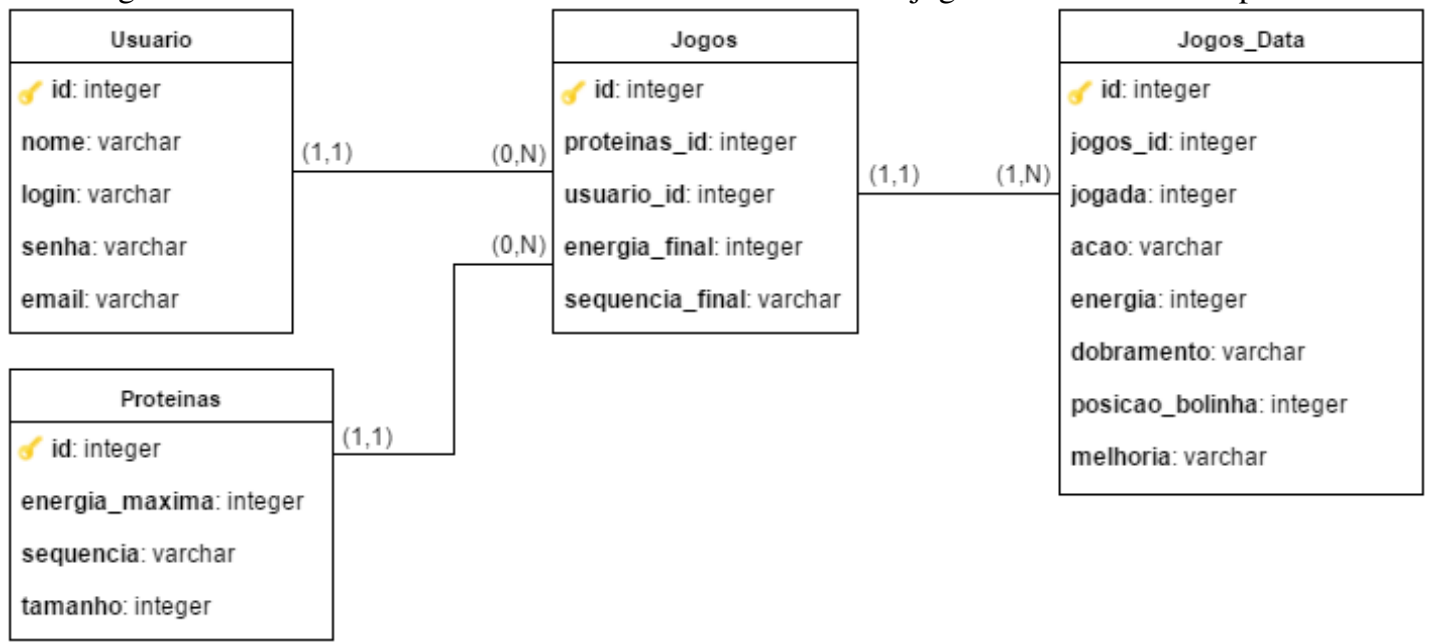

Esta Tabela contém um relacionamento de 1:N com a Tabela Jogos, onde uma proteína pode ter zero ou $\mathrm{N}$ jogos e um jogo contém uma proteína.

- Tabela Jogos: A cada jogo feito pelos usuários, é criada uma nova linha nessa tabela, contendo os dados necessários para relacionar o jogo com o usuário e também todas as jogadas feitas. Esta tabela contém um relacionamento de 1:N com a tabela Jogos_Data, onde um jogo pode ter zero ou $\mathrm{N}$ jogadas e uma jogada contém apenas um jogo.

- Tabela Jogos_Data: Esta tabela é a grande ferramenta para a pesquisa, pois nela é armazenada todos os tipos de jogadas que os usuários realizaram em seus jogos. Com isso é possível saber qual o número da jogada, a ação feita nesta jogada, a energia atingida calculada de acordo com a metodologia do modelo HP, o dobramento em que se encontra a estrutura, a posição do aminoácido em que foi feito o dobramento e também uma comparação entre a jogada atual e a anterior, classificando-a como uma jogada que fez uma energia "melhor", "pior"ou "igual", que serão utilizadas nas técnicas de classificação. Portanto são os dados armazenados nesta tabela, que serão utilizados nas técnicas de mineração de dados.

\subsection{Front-end e Back-end}

Para o desenvolvimento do back-end e front-end foram utilizadas as linguagens HTML5, CSS3, PHP e SQL. Na figura 4 é possível analisar a comunicação entre o Front-end, Back-end e Banco de dados, assim como, as tecnologias utilizadas para efetuar as suas requisições.

Foram utilizados HTML5, CSS3 e Javascript para o desenvolvimento do Front-end. Com isso, foi elaborado um Website contendo o jogo integrado, este contém informações sobre o projeto e explicações sobre a jogabilidade (figura 5 e figura 6 ).

Na figura 6 pode-se ver o ambiente do jogo. Onde é renderizado por intermédio de um Canvas. Canvas é um elemento de HTML5 destinado a delimitar uma área para renderização dinâmica de gráficos. Todo o trabalho de criação e animação é realizado através de linguagens de programação dinâmica como Javascript.

Actions PHP são requisitadas por método POST através de Ajax, que é um uso metodológico de tecnologias como Javascript e XML, providas por navegadores, para tornar páginas Web mais interativas com o usuário, utilizando-se de solicitações assíncronas de informações. Portanto, toda vez que o jogador efetuar uma jogada, assim como utilizar as ferramentas fornecidas no front-end. As requisições contêm todos os dados necessários para o objetivo e aplicação da metodologia do projeto. Nas actions são feitas também, a formatação e manipulação das variáveis para serem salvas corretamente e com segurança no banco de dados. 
Figura 4: Fluxograma da comunicação entre, front-end, back-end e banco de dados do jogo de dobramento de proteína.

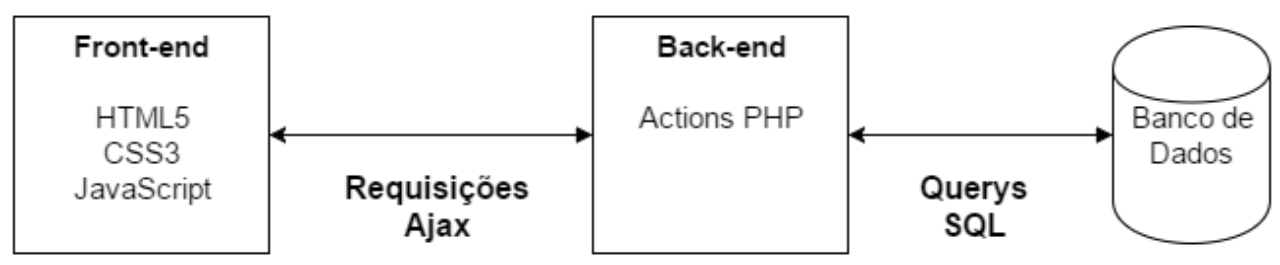

Figura 5: Website do jogo proposto.

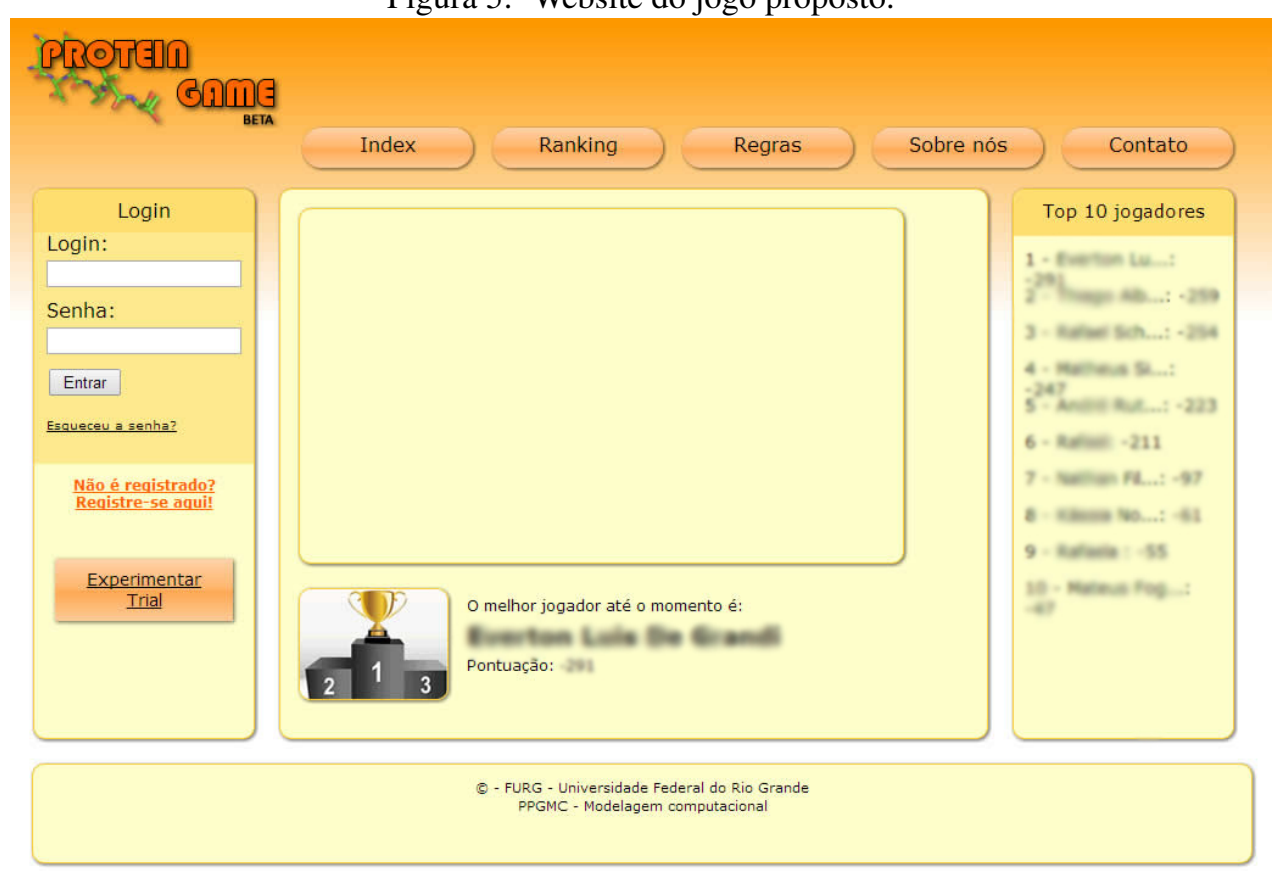

\subsection{Jogabilidade}

Na figura 6 pode-se analizar um pouco da jogabilidade proposta após o jogador selecionar a estrutura que deseja jogar, onde:

1. Mostra a quantidade de energia em que a estrutura se encontra;

2. Botão que possibilita o jogador a finalizar o jogo;

3. Botão onde possibilita o jogador salvar o jogo caso queira continuar a partida que deseja;

4. Botão de ajuda, onde apresenta uma documentação, com informações do jogo e do domínio do problema, como efetuar um dobramento;

5. A estrutura da proteína modelo HP seguindo a metodologia abordada na revisão bibliográfica onde: 1) Esta sobre uma grade; 2) Formada pelos seus aminoácidos simbolizados por círculos brancos(hidrofílicos) e pretos(hidrofóbicos) e suas respectivas ligações simbolizadas por traços pretos; 3) Apenas é possível efetuar dobramentos em ângulos de 90 grau; 4) As ligações hidrofóbicas obtidas simbolizadas por traços verdes e a sobreposição de aminoácidos com um x vermelho. 
Figura 6: Interface: Ambiente do jogo com a estrutura dobrada.

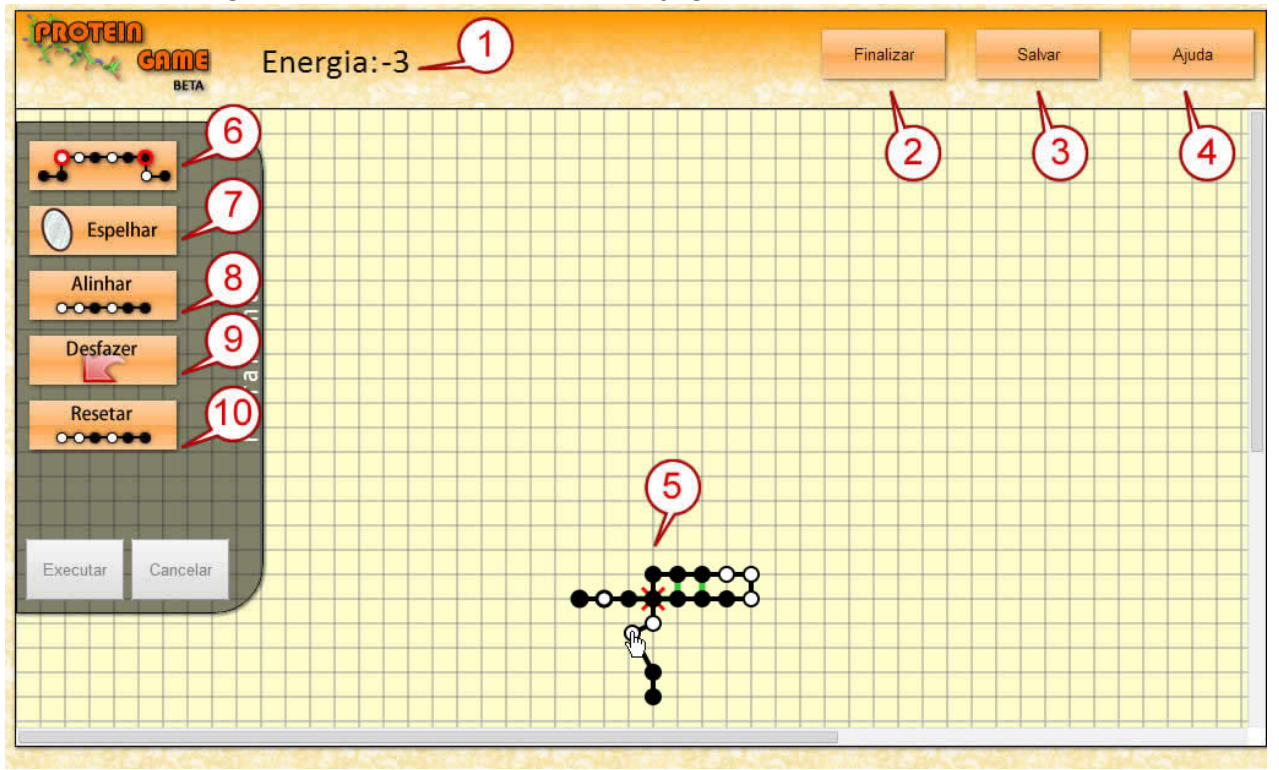

Do item 6 ao item 10, são ferramentas que foram criadas para facilitar o jogador possibilitando efetuar uma sequência de dobramento mais rapidamente:

6. É uma ferramenta que possibilita o jogador selecionar um intervalo de aminoácidos da estrutura e efetuar um dobramento igual ao da Figura 7 (A);

7. Possibilita o jogador a espelhar a estrutura da proteína, como mostra a Figura 7 (B);

8. Possibilita o jogador a selecionar um intervalo de aminoácidos fazendo com que todos os aminoácidos deste intervalo fiquem alinhados, como mostra a Figura 7 (C);

9. Caso o jogador não goste da ultima jogada feita, essa ferramenta possibilita voltar a estrutura ao seu estado anterior;

10. Esta ferramenta faz com que a estrutura da proteína volte ao seu estado inicial como mostra a Figura 7 (D).

\section{Testes e Aplicação do Jogo Sério}

Depois de feito os últimos ajustes na implementação do jogo, este foi testado com alunos de graduação em aulas de professores que cederam uma parte do seu horário.

Para que seja possível o teste, primeiramente foi feita uma breve introdução a respeito do projeto e algumas explicações de como funciona o jogo. Também foi priorizado nas aplicações do jogo, as proteínas S1 (HPHРHНHРPРНHНHРPHН) e S2 (PHPPHPHН HPHНPHНHНH) para que fosse possível obter um volume maior dessas duas estruturas, para os testes. Estas duas estruturas foram escolhidas devido a quantidades de aminoácidos, que é relativamente menor que as demais (figura 1), assim facilitando a jogabilidade para os usuários.

Ao todo, foi possível aplicar o jogo em duas aulas, com duração de uma hora, contendo aproximadamente 40 alunos. Os alunos também foram incentivados a jogar em outros horários e que recomendassem para seus colegas.

Revista Brasileira de Computação Aplicada (ISSN 2176-6649), Passo Fundo, v. 9, n. 1, p. 42-51, abr. 2017 
Figura 7: Exemplos do uso de ferramentas.

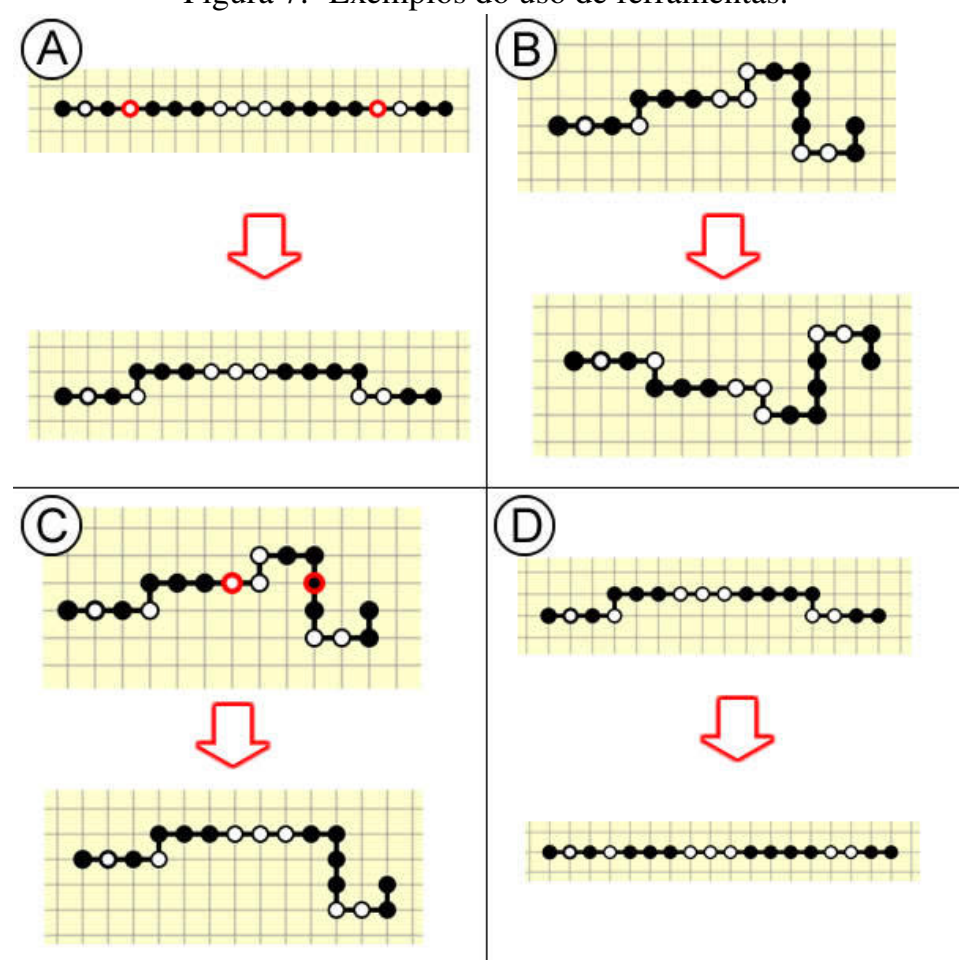

Figura 8: Interface após efetuar o login no Website

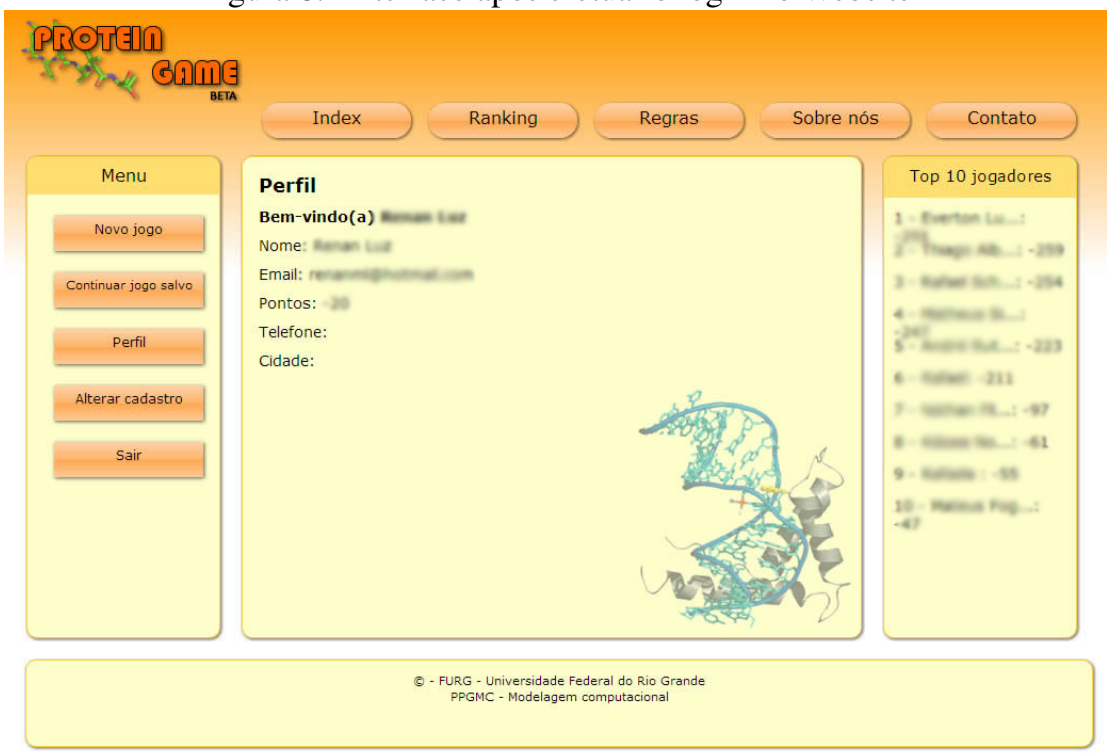

No geral, 44 jogadores foram registrados em nosso banco de dados, obtendo um valor de 401 jogos criados, totalizando 12.059 jogadas. O melhor resultado foi no jogo de id $=425$, com 39 jogadas executadas pelo jogador de id $=46$.

Pelos testes realizados, percebe-se que utilizando as linguagens web de programação, obteve-se um jogo sério de dobramento de proteína disponibilizado na internet, onde qualquer pessoa pode se cadastrar no Website 
Figura 9: Jogador selecionando a proteína que deseja jogar

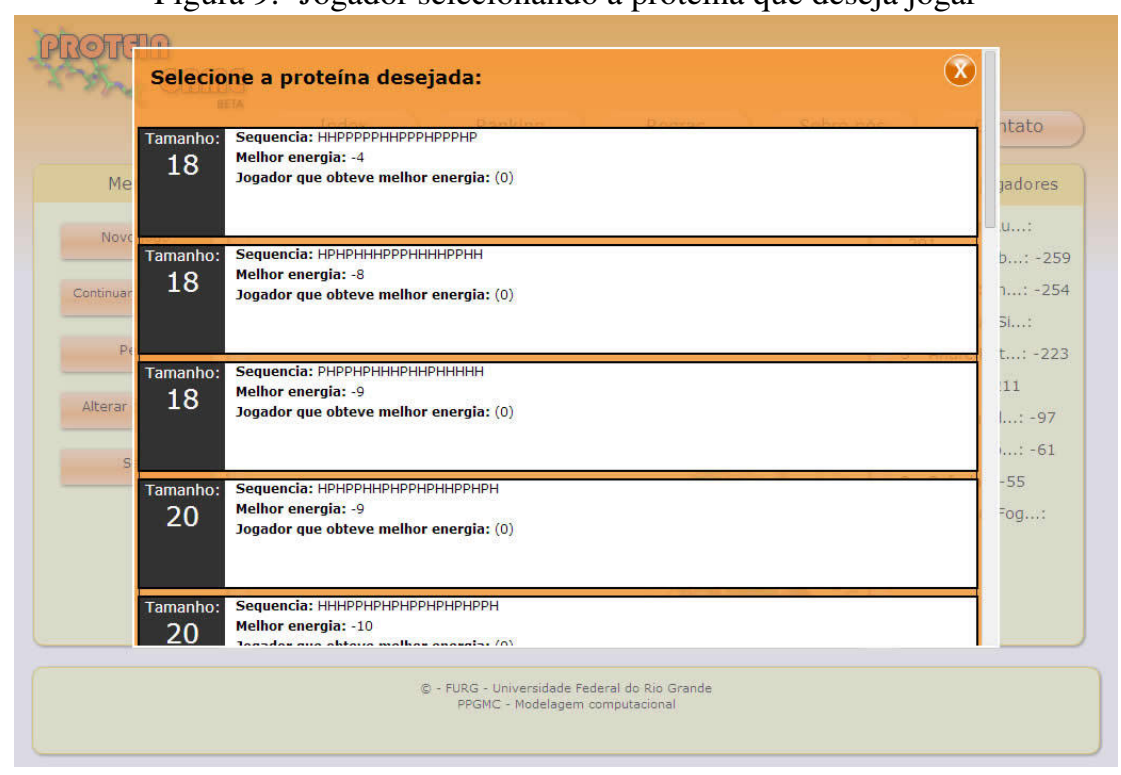

e jogar. Algumas das páginas web e a interface já foram mostradas através das figuras 5 e 6 . Também foram desenvolvidas cinco ferramentas para facilitar a jogabilidade como mostra na figura 6. E pode-se ver mais algumas interfaces como na figura 8 que mostra a tela apresentada ao usuário após efetuar o login, contendo seus dados cadastrados e um menu lateral onde é possível começar um novo jogo ou continuar um já salvo e figura 9 que ao clicar em novo jogo no menu lateral mostra as proteínas disponíveis ao jogador para criar um novo jogo.

Com o desenvolvimento e aplicação do jogo sério, obtive-se um bom volume de dados no banco de dados. Todas as estruturas de proteínas do modelo HP foram inseridas no jogo. Mas, apenas as estruturas menores (com menor número de aminoácidos) foram sugeridas para testes. Durante os testes, os alunos relataram que a experiência durante o jogo foi satisfatória, mostrando que a jogabilidade foi atingida, não prejudicando o objetivo do jogo. Também não foram encontrados erros nos logs da versão final do jogo.

\section{Conclusões e Trabalhos Futuros}

Após o desenvolvimento do jogo proposto, chega-se a conclusão que com as linguagens de programação Web, é possível desenvolver aplicações web complexas e com grandes objetivos, como foi visto nesse projeto.

O uso de um jogo, que em um primeiro momento pode ser visto apenas como uma busca por entretenimento pelos usuários pode ser de grande aprendizagem e auxílio para a ciência.

Com o volume de dados adquiridos através dos jogos realizados, é possível submeter esses dados a técnicas estatísticas de mineração de dados como Árvore de Decisão e Navbayes tendo em vista obter técnicas de dobramento de proteína modelo HP com a ajuda da inteligência humana assim como chegou [2] através do "Fold $i t^{\prime \prime}$.

Desta forma, como trabalhos futuros, pretende-se obter um maior volume de dados em sua base de dados (realizar mais jogos); melhorar as ferramentas fornecidas para os jogadores, facilitando a jogabilidade; tornar o jogo mais dinâmico e multiplayer (capaz de deixar 2 ou mais jogadores interagirem juntos na mesma partida em tempo real);.

Revista Brasileira de Computação Aplicada (ISSN 2176-6649), Passo Fundo, v. 9, n. 1, p. 42-51, abr. 2017 


\section{Referências}

[1] PTITSYN, O. B. A determinable but unresolved problem. The FASEB Journal, v. 10, p. 3-4, 1996.

[2] COOPER, S. et al. Predicting protein structures with a multiplayer online game. Nature, v. 466, p. 756-760, 2010.

[3] MIRANDA, M. J. A inteligência humana: contornos da pesquisa. Paidéia (Ribeirão Preto), v. 12, n. 23, p. 19-29, 2002.

[4] DILL, K. A. Theory for the folding and stability of globular proteinst. Biochemistry, v. 24, p. 1501-1509, 1985.

[5] BAKER, D. A surprising simplicity to protein folding. Nature, v. 405, n. 6782, p. 39-42, 2000.

[6] CHANDRU, V.; DATTASHARMA, A.; KUMAR, V. A. A surprising simplicity to protein folding. Discrete Applied Mathematics, v. 405, n. 127, p. 145-161, 2000.

[7] DINNER, A. et al. Understanding protein folding via free-energy surfaces from theory and experiment. Trends in biochemical sciences, v. 25, p. 331-339, 2000.

[8] PLOTKIN, S.; ONUCHIC, J. Investigation of routes and funnels in protein folding by free energy functional methods. Proceedings of the National Academy of Sciences, v. 97, p. 6509-6514, 2000.

[9] BRANDEN, C.; TOOZE, J. Introduction to Protein Structure. [S.1.]: Garland Science, 1999.

[10] TROVATO, A. et al. What determines the structures of native folds of proteins? Journal of Physics: Condensed Matter, v. 17, p. 1515-1522, 2005.

[11] LEHNINGER; NELSON, D. L.; COX, M. M. Lehninger Principles of Biochemistry. [S.1.]: W. H. Freeman, 2008.

[12] DILL, K. et al. Principles of protein folding - a perspective from simple exact models. Protein science, v. 4, p. 561-602, 1995.

[13] HART, W.; ISTRAIL, S. Hp benchmarks. 2012. Sandia Web Site. Disponível em: <www.cs.sandia.gov/tech_ reports/compbio/tortilla-hp-benchmarks.html>. Acesso em: 23 mar. 2013.

[14] HUIZINGA, J. Homo Ludens: A Study of the Play-Element in Culture. [S.1.]: Beacon Press, 1971.

[15] ALLÉ, J. M. O Grande Livro dos Jogos. [S.1.]: Leitura, 1999.

[16] COOPER, S. et al. The challenge of designing scientific discovery games. Foundations of Digital Games, p. 40-47, 2010.

[17] BURNETT, S. et al. Games that enlist collective intelligence to solve complex scientific problems. Journal of Microbiology e Biology Education, v. 17, n. 1, p. 133-136, 2016. Disponível em: <http://www.asmscience. org/content/journal/jmbe/10.1128/jmbe.v17i1.983>. Acesso em: 23 mar. 2017.

[18] FIALHO, N. Jogos no Ensino de Química e Biologia. [S.1.]: IBPEX, 2007.

[19] PRENSKY, M. Digital Game-Based Learning. [S.1.]: McGraw-Hill Pub. Co., 2004.

[20] NATIONS, D. What is a Web Application? 2014. Abouttech. Disponível em: <www1.folha.uol.com. br/ciencia/2013/05/1274984-jogo-on-line-ajuda-cientistas-a-fazer-mapa-do-cerebro.shtml>. Acesso em: 15 dez. 2014.

[21] PILGRIM, M. HTML5: up and running. [S.1.]: " O’Reilly Media, Inc.", 2010.

[22] RICCA, F.; TONELLA, P. Analysis and Testing of Web Applications. IEEE Computer Society, 2001. 25-34 p. Disponível em: <http://dl.acm.org/citation.cfm?id=381473.381476>. Acesso em: 23 mar. 2013.

Revista Brasileira de Computação Aplicada (ISSN 2176-6649), Passo Fundo, v. 9, n. 1, p. 42-51, abr. 2017 